\title{
Short-term liquid storage of ram semen in various extenders
}

\author{
N. Maksimović ${ }^{1 \#}$, A. Milovanović ${ }^{2}$, T. Barna ${ }^{2}$, V. Caro Petrović ${ }^{1}$, V. Pantelić ${ }^{1}$, M. Lazarević ${ }^{1}$ \\ \& I. Stojanov ${ }^{2}$ \\ ${ }^{1}$ Institute for Animal Husbandry, Auto put 16, 11080 Zemun-Belgrade, Republic of Serbia \\ ${ }^{2}$ Scientific Veterinary Institute "Novi Sad", 21000 Novi Sad, Republic of Serbia
}

(Received 29 March 2018; Accepted 12 July 2018; First published online 15 August 2018)

Copyright resides with the authors in terms of the Creative Commons Attribution 4.0 South African Licence.
See: http://creativecommons.org/licenses/by/4.0/za
Condition of use: The user may copy, distribute, transmit and adapt the work, but must recognise the authors and the South African
Journal of Animal Science.

\begin{abstract}
The aim of this study was to investigate the effects of three extenders on ram sperm quality after short-term liquid storage (24 hours' holding time). The study included 20 crossbred rams (Pirot Pramenka $x$ Wurttemberg $x$ lle de France), 12 months old. Animals were housed at the experimental sheep farm of the Institute for Animal Husbandry in Belgrade, Serbia. Semen was collected through electro ejaculation. The ejaculates were obtained from single services and routine field analysis of the semen was performed immediately after the collection. The semen was split and diluted with three extenders, namely Optidyl ${ }^{\circledR}$, Andromed $^{\circledR}$ and ultrahigh temperature processed (UHT) milk, in ratios of $1: 50$ or $1: 100$. The ejaculates were examined for sperm motility variables (sperm cell motility percentage, the progressive motility percentage, curvilinear velocity (VCL), straight line velocity (VSL), average path velocity (VAP), sperm linearity (LIN), straightness (STR), amplitude of lateral sperm head displacement (ALH), beat cross frequency (BCF) and circular tracks), and sperm morphology (live sperm percentage, percentage of normal sperm forms with intact acrosome, percentage of abnormal sperm forms and total damaged acrosome) by computer-assisted sperm analysis (CASA) and classic sperm cytology after supravital eosin/nigrosine/trypan blue staining, respectively. It was observed that the type of extender used in diluting ram semen is an important factor in the successful short-term liquid preservation (at $4{ }^{\circ} \mathrm{C}$ ) of ram spermatozoa. In conclusion, this study showed that egg yolk (Optidyl) and soybean (Andromed)-based extenders gave better results of both sperm morphology and sperm motility parameters compared with UHT milk.
\end{abstract}

Keywords: Diluents, morphology, motility, sperm

\# Corresponding author: nevena_maksimovic@yahoo.com

\section{Introduction}

Semen extenders have been designed to protect and maintain spermatozoa during the processing and storage of semen (Paulenz et al., 2002). Extender as a medium creates optimal conditions for the extension of the life of sperm and, most importantly, preserves the reproductive ability of semen. Extender replaces the seminal plasma and assumes its role (Vaić, 2011). In other words, extender maintains motility and fertilizing capacity, and preserves sperm membrane integrity. It is also necessary to dilute semen to obtain a larger number of doses from the ejaculate.

The possibility of spermatozoa keeping their biological potential and genetic information after dilution and storage is important for sheep breeding practice. The practical use of liquid semen under farm conditions may be facilitated in case the semen is diluted and stored (Gundogan, 2009).

Many extenders can be used to preserve ram semen, commercial and non-commercial. Currently, two kinds of semen extenders are in use, that is, animal-source lipoprotein-based extenders and plant lipoprotein source-based extenders (Gil et al., 2003; Kasimanickam et al., 2011). The animal source is mostly egg yolk and the plant source is soybean lecithin. Whole or skimmed milk is also used to preserve semen (Kakar \& Ganguli, 1978; Batellier et al,, 2001; Bergeron \& Manjunath, 2006; Rahman, 2014). Plant protein sources were introduced to replace animal lipoproteins and thus avoid resulting diseases and retain the biosecurity from trans-boundary diseases (Rehmana et al., 2013). 
Various studies tested differences in sperm activity of ram semen diluted in extenders and stored for short or long periods. Rahman (2014) found that comparatively, skim milk extender gave better protection during preservation process in terms of chilling and freezing ram semen than egg yolk-based extender. On the other hand, Soltanpour \& Moghaddam (2014) stated that a diluent of citrate egg yolk had better sperm protection ability than milk-based extenders after eight days of liquid storage at $4{ }^{\circ} \mathrm{C}-$ according to sperm motility, pH and sperm viability. Research conducted by Kulaksiz et al. (2012), showed that the skimmed milk extender with egg yolk secured the best liquid storage and post-thaw motility compared with egg yolk only and egg yolk-free extenders. The percentage of total abnormal spermatozoa was lowest in skimmed milk + egg yolk extender on the first day of storage. Forouzanfar et al. (2010) concluded that lecithin could be used as a substitute for egg yolk in cryopreservation of ram semen, as they obtained sperm motility, post thaw viability and cleavage rates with soybean lecithin-based extender to be $51.9 \pm 4.8 \%, 48.1 \pm 3.5 \%$ and $79.6 \pm$ $3.9 \%$, respectively.

Artificial insemination (Al) allows for the rapid dissemination of genetic material from a small number of superior sires to a large number of females (Vishwanath \& Shannon, 1997). Semen from farm animals used for this purpose can be stored in liquid form at $4{ }^{\circ} \mathrm{C}$ for a short time or it may be kept for a long period in a cryopreserved state with liquid nitrogen (Maxwell \& Watson, 1996). Storage diluents and techniques have been developed and adapted with the aim of improving the cryopreservation of ram semen, but fertility after cervical Al with frozen-thawed sperm remains significantly lower than that achieved with fresh semen (Kulaksiz et al., 2012).

Studies on extenders are important in determining the most suitable extenders, at optimal concentrations for a particular species. Diluted and cooled ram semen is an alternative choice to frozen semen if insemination is done within a short period, since damaging effects are less pronounced in diluted and chilled semen than in frozen thawed semen. Therefore, the aim of this study was to investigate the effect of milk, egg yolk- and soybean-based extenders on sperm parameters of ram semen during liquid storage for 24 hours at $4{ }^{\circ} \mathrm{C}$.

\section{Materials and Methods}

Research was carried out at the experimental sheep farm of the Institute for Animal Husbandry, Zemun, Belgrade. It included 20 crossbred rams (autochthonous breed Pirot Pramenka x Wurttemberg $x$ Ile de France), 12 months old. This is the age at which rams are usually introduced into breeding by on-farm practices, regardless of season. Animals were kept indoors, fed alfalfa hay and a $16 \%$ protein concentrate supplemented with vitamins and minerals. Prior to this study all rams were sexually inexperienced, but had previously been subjected to semen collection twice, at the age of 9 and 11 months, to keep track of sperm maturation progress.

The extenders used in the study were i) Andromed $^{\circledR}$, which was prepared according to the manufacturer's (Minitübe, Tiefenbach, Germany) instructions. Andromed is an egg yolk-free medium, a commercial diluent, that contains soybean lecithin extract; ii) Optidyl ${ }^{\circledR}$, which is a commercial extender containing ionized egg yolk, prepared according to manufacturer's (Cryo-vet, France) instructions; and iii) ultra-high temperature (UHT) milk from the store.

Semen was collected from each ram using an electro ejaculator. The ejaculates were obtained from single services, and the routine field analysis of the native semen was performed immediately after the collection. Volume of ejaculates was $1.75 \mathrm{~mL}$ on average (range 0.50 to $2.60 \mathrm{~mL}$ ). All of the ejaculates were suitable for evaluation. The semen was split and then diluted with three extenders, namely Optidyl, Andromed and UHT milk, in a ratio $1: 2$, transported and analysed in the laboratory within 3-5 hours of collection. Final semen dilution was set to $1: 50$ or $1: 100$, depending on the approximated density of ejaculates. The ejaculates were examined for sperm motility parameters and sperm morphology. Sperm motility parameters were assessed using computer-assisted semen analysis (CASA) integrated system for the analysis of semen (ISAS V.1.2., Proiser, Spain). The measured motility variables included sperm cell motility percentage, progressive motility percentage, curvilinear velocity $(\mu \mathrm{m} / \mathrm{s})$, straight line velocity $(\mu \mathrm{m} / \mathrm{s})$, average path velocity $(\mu \mathrm{m} / \mathrm{s}$ ), sperm linearity (as a measure of a curvilinear path VSL/VCL), STR (as the linearity of the average path VSL/VAP), amplitude of lateral sperm head displacement $(\mu \mathrm{m})$ and beat cross frequency $(\mathrm{Hz})$ (Mortimer, 1997). Circular tracks (\%) were also assessed. For sperm morphology, including live sperm percentage, percentage of normal sperm forms with intact acrosome, percentage of abnormal sperm forms and total damaged acrosome, semen was stained with eosin-nigrosin-trypan blue stain and examined by light microscope under oil immersion with final magnification of $1000 \times$.

Data were analysed using Statistica for Windows 7 (StatSoft Inc.). Kruskal-Wallis's test was performed to determine the effect of extender on sperm quality parameters. The comparison of the means was done by Mann-Whitney $U$ test. Data were presented as the mean \pm standard error of mean (SE). Analyses were performed for the significance level of $5 \%$ and $1 \%$. 
Animal experimentation was conducted within standard ethical norms.

\section{Results}

The effect of extender on sperm motility parameters after collection (initial analysis) is presented in Tables 1 and 2.

Table 1 Mean $( \pm$ SE) for motility and sperm velocity parameters in various extenders after collection (initial analysis)

\begin{tabular}{lccccc}
\hline Extender & Motility $^{* *}, \%$ & $\begin{array}{c}\text { Progressive } \\
\text { motility, } \%\end{array}$ & VAP $^{*}, \boldsymbol{\mu m} / \mathbf{s}$ & VSL, $\boldsymbol{\mu m} / \mathbf{s}$ & VCL $^{*}, \boldsymbol{\mu m} / \mathbf{s}$ \\
\hline Andromed & $72.35^{\mathrm{A}} \pm 2.48$ & $15.38 \pm 3.03$ & $112.3^{\mathrm{a}} \pm 8.16$ & $61.03 \pm 7.7$ & $204.32^{\mathrm{a}} \pm 8.51$ \\
Optidyl & $71.27^{\mathrm{A}} \pm 2.79$ & $20.68 \pm 2.54$ & $112.68^{\mathrm{a}} \pm 9.88$ & $68.82 \pm 7.08$ & $201.7^{\mathrm{a}} \pm 8.11$ \\
Milk & $51.7^{\mathrm{B}} \pm 7.69$ & $27.13 \pm 4.66$ & $80.66^{\mathrm{b}} \pm 12.01$ & $57.88 \pm 8.44$ & $72.55^{\mathrm{b}} \pm 14.17$
\end{tabular}

VAP: average path velocity, VSL: straight line velocity, VCL: curvilinear velocity

${ }^{\mathrm{a}, \mathrm{b}}$ Column means with different superscripts differ significantly at $P<0.05^{*}$

${ }^{A, B}$ Column means with different superscripts differ significantly at $P<0.01^{\star \star}$

Table 2 Mean $( \pm$ SE) for sperm motility parameters in different extenders after collection (initial analysis)

\begin{tabular}{lccccc}
\hline Extender & STR, \% & LIN, \% & ALH $^{*}, \boldsymbol{\mu m}$ & BCF ${ }^{*}, \mathbf{H z}$ & $\begin{array}{c}\text { Circular tracks } \\
\%\end{array}$ \\
\hline Andromed & $52.34 \pm 3.51$ & $28.93 \pm 2.79$ & $4.39^{\mathrm{a}} \pm 0.22$ & $15.25^{\mathrm{b}} \pm 1.09$ & $62.47^{\mathrm{A}} \pm 3.51$ \\
Optidyl & $60.26 \pm 2.23$ & $33.14 \pm 2.13$ & $4.47^{\mathrm{a}} \pm 0.09$ & $17.98^{\mathrm{a}} \pm 0.68$ & $59.47^{\mathrm{A}} \pm 2.88$ \\
Milk & $54.29 \pm 7.37$ & $31.34 \pm 4.31$ & $2.86^{\mathrm{b}} \pm 0.39$ & $17.53^{\mathrm{a}} \pm 2.41$ & $31.61^{\mathrm{B}} \pm 4.9$
\end{tabular}

STR: straightness, LIN: sperm linearity, ALH: amplitude of lateral sperm head displacement, BCF: beat cross frequency ${ }^{a, b}$ Column means with different superscripts differ significantly at $P<0.05^{\star}$

As shown in Table 1, the effect of extender was significant for motility percentage, VAP and VCL, but not for progressive motility. Sperm motility percentage was lowest in sperm diluted in milk $(51.7 \pm 7.69)$, while progressive motility showed the highest value in milk extender. Andromed and Optidyl gave approximately equal motility percentages $(72.35 \pm 2.48$ and $71.27 \pm 2.79)$, but progressive motility was higher in Optidyl. VAP, VSL and VCL were lowest for sperm diluted in UHT milk.

Straightness and linearity (Table 2) were highest for Optidyl, but the difference was not significant. Beat-cross frequency was higher for Optidyl and UHT milk than for Andromed $(P<0.05)$.

Data on the effect of extender on sperm motility parameters in semen held for 24 hours at $4{ }^{\circ} \mathrm{C}$ are presented in Tables 3 and 4.

Table 3 Mean $( \pm$ SE) motility and sperm velocity parameters in different extenders after 24 hours' holding time

\begin{tabular}{lccccc}
\hline Extender & Motility $^{*}, \%$ & $\begin{array}{c}\text { Progressive } \\
\text { motility, \% }\end{array}$ & VAP $^{*}, \boldsymbol{\mu m} / \mathbf{s}$ & VSL $^{*}, \boldsymbol{\mu m} / \mathbf{s}$ & VCL $^{* *}, \boldsymbol{\mu m} / \mathbf{s}$ \\
\hline Andromed & $70.27^{\mathrm{b}} \pm 4.88$ & $22.26 \pm 2.67$ & $151.98^{\mathrm{a}} \pm 11.18$ & $95.49^{\mathrm{a}} \pm 8.47$ & $240.18^{\mathrm{A}} \pm 12.92$ \\
Optidyl & $79.41^{\mathrm{a}} \pm 4.27$ & $23.34 \pm 2.43$ & $151.74^{\mathrm{a}} \pm 9.53$ & $92.05^{\mathrm{a}} \pm 7.2$ & $228.86^{\mathrm{A}} \pm 11.92$ \\
Milk & $62.45^{\mathrm{b}} \pm 5.07$ & $17.73 \pm 3.18$ & $108.23^{\mathrm{b}} \pm 14.52$ & $72.58^{\mathrm{b}} \pm 11.06$ & $163.36^{\mathrm{B}} \pm 19.8$
\end{tabular}

VAP: average path velocity, VSL: straight line velocity, VCL: curvilinear velocity

${ }_{a, b}$ Column means with different superscripts differ significantly at $P<0.05^{*}$

${ }^{A}, \mathrm{~B}$ Column means with different superscripts differ significantly at $P<0.01^{* \star}$ 
Table 4 Mean $( \pm$ SE) sperm motility parameters in different extenders after 24 hours' holding time

\begin{tabular}{lccccc}
\hline Extender & STR, \% & LIN, \% & ALH $^{*}, \boldsymbol{\mu m}$ & BCF $^{* *}, \mathbf{H z}$ & $\begin{array}{c}\text { Circular } \\
\text { tracks }\end{array} \%$ \\
\hline Andromed & $62.18 \pm 2.24$ & $39.21 \pm 2.36$ & $4.43^{\mathrm{a}} \pm 0.21$ & $20.66^{\mathrm{A}} \pm 0.68$ & $46.22^{\mathrm{b}} \pm 4.06$ \\
Optidyl & $60.22 \pm 2.06$ & $39.78 \pm 1.86$ & $3.98^{\mathrm{b}} \pm 0.17$ & $20.32^{\mathrm{A}} \pm 0.69$ & $52.06^{\mathrm{a}} \pm 3.3$ \\
Milk & $65.45 \pm 2.35$ & $44.72 \pm 3.16$ & $3.48^{\mathrm{b}} \pm 0.28$ & $15.53^{\mathrm{B}} \pm 1.63$ & $36.03^{\mathrm{b}} \pm 4.72$
\end{tabular}

STR: straightness, LIN: sperm linearity, ALH: amplitude of lateral sperm head displacement, BCF: beat-cross frequency

${ }_{a, b}$ Column means with different superscripts differ significantly at $P<0.05^{*}$

$\mathrm{A}, \mathrm{B}$ Column means with different superscripts differ significantly at $P<0.01^{* *}$

Data presented in Table 3 shows that sperm diluted in Optidyl and Andromed had higher values of motility and sperm velocity parameters after 24 hours' holding time compared with UHT milk. This difference was significant for VAP, VSL and VCL. Motility percentage was also influenced by extender $(P<0.05)$, but Optidyl had the highest value and differed from the other two extenders.

Straightness and linearity (Table 4) were both highest for UHT milk, but the difference was not significant. Andromed diluted semen showed the highest value for ALH, which was different $(P<0.05)$ from the ALH value obtained from Optidyl- and UHT milk-diluted semen. Beat-cross frequency was similar in value for Andromed and Optidyl and was higher compared with BCF obtained for milk-diluted semen ( $P$ $<0.01)$.

Table 5 shows sperm morphology parameters (live sperm, normal sperm forms with intact acrosome, sperm cells with damaged acrosome and abnormal sperm forms) in native semen in the moment of collection and in different extenders, 24 hours after collection.

Table 5 Sperm morphology parameters at collection and after 24 hours in various extenders

\begin{tabular}{lcccc}
\hline Extender & Live sperm* $\%$ & $\begin{array}{c}\text { Normal forms with } \\
\text { intact acrosome }\end{array} \%$ & $\begin{array}{c}\text { Damaged } \\
\text { acrosome }\end{array} \%$ & Abnormal forms, \% \\
\hline $\begin{array}{l}\text { Native semen at } \\
\text { collection }\end{array}$ & $45.44^{\mathrm{ab}} \pm 4.74$ & $41^{\mathrm{ab}} \pm 4.49$ & $32^{\mathrm{BC}} \pm 3.74$ & $9 \pm 1.57$ \\
Andromed 24 h & $37.17^{\mathrm{bc}} \pm 5.38$ & $32.05^{\mathrm{bC}} \pm 4.56$ & $43.5^{\mathrm{AB}} \pm 4.72$ & $11.11 \pm 1.88$ \\
Optidyl 24 h & $53.61^{\mathrm{a}} \pm 5.24$ & $46.05^{\mathrm{a}} \pm 4.53$ & $25.55^{\mathrm{C}} \pm 2.75$ & $11.33 \pm 2.03$ \\
Milk 24 h & $29.55^{\mathrm{c}} \pm 5.88$ & $25.39^{\mathrm{C}} \pm 5.44$ & $57.44^{\mathrm{A}} \pm 5.2$ & $12.22 \pm 2.04$
\end{tabular}

$\overline{a, b}$ Column means with different superscripts differ significantly at $P<0.05^{\star}$

${ }^{\mathrm{A}, \mathrm{B}}$ Column means with different superscripts differ significantly at $P<0.01^{\text {** }}$

Semen diluted in Optidyl extender had the highest percentage of live sperm and normal sperm forms with intact acrosome 24 hours after collection and the lowest percentage of sperm cells with damaged acrosome. Compared with other two extenders, these were different at $P<0.05$ and $P<0.01$, respectively. Andromed diluted semen also gave better results of these morphology parameters compared with milk extended semen, even though difference was not significant. Percentage of abnormal sperm forms was somewhat higher in milk than in the other two extenders, but the difference was not significant.

\section{Discussion}

Sperm motility is considered one of the most important factors that affect male fertility. The presence of a high percentage of motile sperm in the ejaculate is critical for proper sperm transport and fertilization. However, great variations have been described in the subjective estimation of sperm motility, even assessing the same ejaculates (Contri et al., 2010). The development of computer-assisted semen analysis (CASA) allowed more objective motility assessments based on several specific motility parameters describing the movements of spermatozoa. A study that employed a CASA showed that the semen samples with higher values of curvilinear velocity, straight-line velocity and average-path velocity parameters provided higher rates of pregnancy (Donnelly et al., 1998). Each of these velocities describes a different aspect of the 
progression of the spermatozoon and, along with other parameters such as linearity, straightness, the amplitude of lateral head displacement and others, is used to further describe the trajectory.

The results of the present study showed that the extender influenced the sperm motility parameters in semen evaluated by CASA. Ejaculates diluted with Optidyl and Andromed gave better results of sperm motility than milk-diluted semen in both periods (initial analysis and 24 hours' holding time). Many of the previous studies also showed differences among sperm motility parameters that were influenced by the extender used for dilution (Kulaksiz et al., 2012; Mostafapor \& Ardebili, 2014; Soltanpour \& Moghaddam, 2014). However, different studies gave advantages to different extenders. Rahman (2014) found skim milk extender better than egg yolk extender, which is in contrast with that of Soltanpour \& Moghaddam (2014), who found egg yolk extender to be better than milk-based extenders. Kulaksiz et al. (2012) gave the advantage to skimmed milk mixed with egg yolk. Forouzanfar et al. (2010) stated that lecithin-based extender could be an adequate replacement for egg yolk. On the other hand, Lopez et al. (1999) observed no differences among extenders (sodium citrate, Tris, and milk-based extenders) when subjected to liquid storage at $4{ }^{\circ} \mathrm{C}$. The results of the present study are in agreement with findings of Forouzanfar et al. (2010) and Soltanpour \& Moghaddam (2014).

The only sustainable success after vaginal and cervical insemination of sheep with frozen-thawed semen was achieved in Norway (Paulenz et al., 2005, 2007). Procedures for semen dilution involved a combination of non-fatty milk powder and egg yolk extender. This implies the need to consider possible the positive effects of simultaneous use of different extenders on high conception rate.

During liquid storage of ram semen there is usually a decline in motility parameters, as documented in various studies (Joshi et al., 2001; Kheradmand et al., 2006; Azizunnesa et al., 2014). The findings of the present study, however, showed a certain increase in motility of spermatozoa from semen extended in milk and Optidyl, going from $51.7 \%$ and $71.27 \%$ to $62.45 \%$ and $79.41 \%$ after 24 hours' holding time, respectively. Only the sperm diluted in Andromed showed some decline in motility percentage from 72.35 to 70.27 during 24 hours. The same trend of increasing values was observed for almost all sperm motility pattern parameters and sperm velocity parameters. Ram spermatozoa are sensitive to sudden changes in temperature and environment and, sometimes, due to the shock from collection, sperm cells become initially inactive. However, given the time and optimal environment they reactivate and resume normal function. In the findings of Mostafapor \& Ardebili (2014) some sperm velocity and motility pattern parameters, such as VAP, STR, and LIN, had higher values after one to two hours' holding time than at the initial analysis, even though motility percentage decreased to some extent.

Unlike motility percentage, progressive motility percentage did not show significant differences between extenders, either after collection, or after 24 hours' holding time. However, it was observed that in some of the semen samples, sperm cells had almost completely lost their activity 24 hours after collection, which was the most pronounced in milk extender (6/20 in milk compared with 2-3/20 in Optidyl and Andromed). This suggests that for some semen, milk may not be favourable as an extender.

Results of the present study showed that sperm velocity parameters (VAP, VSL, and VCL) of the sperm diluted in Andromed and Optidyl had higher values compared with milk, both after collection and 24 hours' holding time. The measurement of velocity is an indirect indicator of mitochondrial function (Graham et al., 1984) of spermatozoa and is associated with fertility (Aitken, 1990).

Morphology of sperm, particularly the acrosomal status (Yanagimachi, 1994), is an important indicator of fertility. Even though a spermatozoon may be viable and possess progressive motility, if its acrosome is damaged or lost, it will not be able to fertilize an oocyte. A high proportion of abnormal sperm cells adversely affect fertility. The present study showed a statistically significant effect of extender on sperm morphology parameters, with Optidyl giving the best results for short-term preservation of liquid semen, in highest live cell percentage, highest normal cell with intact acrosome percentage and lowest percentage of sperm cell with damaged acrosome.

\section{Conclusions}

From the present results it was observed that the type of extender used in diluting ram semen is an important factor in successful short-term liquid preservation (at $4{ }^{\circ} \mathrm{C}$ ) of ram spermatozoa.

This study showed that egg yolk (Optidyl)- and soybean (Andromed)-based extenders gave better results of sperm morphology and sperm motility parameters, compared with UHT milk. These findings suggest that it is better to use the two commercial extenders (especially Optidyl) and avoid using solely UHT milk to dilute ram semen for short-term liquid storage. Additionally, in terms of morphology, Optidyl provided the best environment for spermatozoa and therefore could be regarded as the best choice for short-term liquid storage of ram semen. 
Acknowledgments

Research was financed by the Ministry of Education, Science and Technological Development, Republic of Serbia, project TR 3105.

\section{Authors' Contributions}

Sample collection and laboratory work AM, TB and NM. Data analysis and writing of manuscript NM. Editing and final approval of the manuscript AM, VCP, VP, ML and IS.

\section{Conflict of Interest Declaration}

The authors declare that they have no conflicts of interest with regard to this work.

\section{References}

Aitken, R.J., 1990. Motility parameters and fertility. In: C. Cagnon, (ed). Controls of sperm motility: Biological and clinical aspects. CRC, Boca Raton. pp. 285-302.

Azizunnesa, Zohara, B.F., Bari, F.Y. \& Alam, M.G.S., 2014. Effects of proportion of egg yolk and preservation time on chilled semen from indigenous rams. GSTF J. Vet. Sci. (JVet) 1, 1, 18-26.

Batellier, F., Idament, M.V., Fauquant, J., Duchamp, G., Arnaud, G., Yvon, J.M. \& Magistrini, M., 2001. Advances in cooled semen technology. Anim. Reprod. Sci. 68, 181-190.

Bergeron, A. \& Manjunath, P., 2006. New insights towards understanding the mechanisms of sperm protection by egg yolk and milk. Mol. Reprod. Dev. 73, 1338-1344

Contri, A., Valorz, C., Faustini, M., Wegher, L. \& Carluccio, A., 2010. Effect of semen preparation on CASA motility results in cryopreserved bull spermatozoa. Theriogenology 74, 424-435.

Donnelly, E.T., Lewis, E.S., McNally, A.J. \& Thompson, W., 1998. In vitro fertilization and pregnancy rates: The influence of sperm motility and morphology on IVF outcome. Fertil. Steril. 70, 2, 305-314.

Forouzanfar, M., Sharafi, M. \& Hosseini, M.S., Ostadhosseini, S., Hajian, M., Hosseini, L., Abedi, P., Nili, N., Rahmani, R.H., Nasr-Esfahani, H.M., 2010. In vitro comparison of egg yolk-based and soybean lecithin-based extenders for cryopreservation of ram semen. Theriogenology $73,4,480-487$.

Gil, J., Lundhein, N., Soderquist, L. \& Martines-Rodriguez, H., 2003. Influence of extender, temperature and addition glycerol on post thaw sperm parameters in ram semen. Theriogenology 59, 1241-55.

Graham, E.F., Schmel, M.K. \& Deyo, R.C.M., 1984. Cryopreservation and fertility of fish, poultry and mammalian spermatozoa. Proceedings of 10th Technical Conference on Artificial Insemination and Reproduction. National Association of Animal Breeders, Columbia, MO, 44-48.

Gundogan, M., 2009. Short term preservation of ram semen with different extenders. Kafkas Univ. Vet. Fak. Derg. 15, 429-435.

Joshi, A., Bag, S., Naqvi, S.M.K., Sharma, R.C., Rawat, P.S. \& Mittal, J.P., 2001. Effect of short-term and long-term preservation on motion characteristics of Garole ram spermatozoa: A prolific micro sheep breed of India. AsianAustralas J. Anim. Sci. 14, 11, 1527-1533.

Kakar, S.S. \& Ganguli, N.C., 1978. Milk as an extender for semen: A review. Indian J. Anim. Sci. 48, 11, 777-90.

Kasimanickam, R., Kasimanickam, V., Tibracy, A. \& Pelzer, K., 2011. Effect of semen extenders on sperm parameters of ram semen during liquid storage at $4^{\circ} \mathrm{C}$. Small Rumin. Res. 99, 208-13.

Kheradmand, A., Babaei, H. \& Abshenas, J., 2006. Comparative evaluation of the effect of antioxidants on the chilledstored ram semen. Iran. J. Vet. Res. 7, 4, 40-45.

Kulaksiz, R., Çebi, Ç. \& Akçay, E., 2012. The effect of different extenders on the motility and morphology of ram sperm frozen or stored at $4{ }^{\circ} \mathrm{C}$. Turk. J. Vet. Anim. Sci. 36, 2, 177-182.

Lopez, A., Söderquist, L.\& Rodriguez-Martinez, H., 1999. Sperm viability in ram semen diluted and stored in three different extenders. Acta Vet. Scand. 40, 1-9.

Maxwell, W.M.C. \& Watson P.F., 1996. Recent progress in the preservation of ram semen. Anim. Reprod. Sci. 42, 1-4, 55-65.

Mortimer, S.T., 1997. A critical review of the physiological importance and analysis of sperm movement in mammals. Hum. Reprod. Update 3, 403-439.

Mostafapor, S. \& Ardebili, F.F., 2014. Effects of diluting medium and holding time on sperm motility analysis by CASA in ram. Vet. Res. Forum 5, 2, 101-105.

Paulenz, H., Soderquist, L., Parez-Pe, R. \& Berg, K.A., 2002. Effect of different extenders and storage temperatures on sperm viability of liquid ram semen. Theriogenology $57,823-836$.

Paulenz, H., Söderquist, L., Adnøy, T., Nordstoga, A.B. \& Berg, K.A., 2005. Effect of vaginal and cervical deposition of semen on the fertility of sheep inseminated with frozen-thawed semen. Vet. Rec. 156, 12, 372-375.

Paulenz H., Ådnøy, T. \& Söderquist, L., 2007. Comparison of fertility results after vaginal insemination using different thawing procedures and packages for frozen ram semen. Acta Vet. Scand. 49, 1, 26.

Rahman, S., 2014. Preservation of indigenous ram semen with skim milk diluent. MSc thesis, Faculty of Veterinary Science, Bangladesh Agricultural University, Mymensingh.

Rehmana, U.F., Zhaoa, C., Shaha, M.A., Qureshib, M.S. \& Wang, X., 2013. Semen extenders and artificial insemination in ruminants. Veterinaria 1, 1-8.

Soltanpour, F. \& Moghaddam G., 2014. Effect of diluents on storage of ram semen. JAAS 2, 6, 179-183.

Vaić, D., 2011. 'Optidyl' is a concentrated extender for freezing of bulls semen doses. In: Proceedings of XXV Conference of Agronomist, Veterinarians and Technologists. Belgrade, Serbia, 101-104 (in Serbian, English summary). 
Vishwanath, R. \& Shannon P., 1997. Do sperm cells age? A review of the physiological changes in sperm during storage at ambient temperature. Reprod. Fertil. Dev. 9, 321-331.

Yanagimachi, R., 1994. Mammalian fertilization. In: E. Knobil \& J. Neill (eds). The Physiology of Reproduction. 2nd edition. Raven, New York, pp. 189-317. 